\title{
PREVALENCE OF MALOCCLUSIONS IN A SAMPLE OF 4-5-YEAR-OLD BULGARIAN CHILREN
}

\author{
Keti Yovcheva ${ }^{1 a^{*}}$, Miroslava Yordanova $^{\text {1b }}$, Svetlana Yordanova ${ }^{1 c}$, Nina Musurlieva ${ }^{2 d}$ \\ 1Department of Orthodontics, Faculty of Dental Medicine, Medical University - Plovdiv, Bulgaria \\ 2Department of Social Medicine and Public Health, Faculty of Public Health, Medical University - Plovdiv, Bulgaria
}

\author{
${ }^{a} \mathrm{DMD}$ \\ ${ }^{b} \mathrm{DMD}, \mathrm{PhD}$ \\ 'DMD, PhD \\ ${ }^{\mathrm{D} D M D}, \mathrm{PhD}$
}

Academic Editor: Ioan Danilă, DDS, PhD, Professor,"Gr. T. Popa” University of Medicine and Pharmacy Jassy, Jassy, Romania

Cite this article:

Yovcheva K, Yordanova M, Yordanova S, Musurlieva N. Prevalence of malocclusions in a sample of 4-5-year-old Bulgarian children. Stoma Edu J. 2017;4(1):66-71.

The aim of this study is to estimate the prevalence of malocclusions in a sample of 4-5-year-old children.

Methodology: 471 boys and girls participated in this observational cross-sectional epidemiological study. The presence of spacing, no spacing and crowding, anteroposterior, transverse and vertical occlusion relationships was assessed and analyzed.

Results: Normal occlusal relationships were found in $35.6 \%$ of all children. Generalized spacing was found in $78.2 \%$ of the subjects, followed by no spacing in $16.1 \%$ and crowding in $5.7 \%$, respectively. Class I canine relationship was found in $64.1 \%$ of the children, followed by Class II in $29.1 \%$ and Class III in $9.6 \%$. A flush terminal molar relationship was found in approximately $70 \%$ of the children, followed by mesial and distal molar relationships equally distributed. An increased and decreased overjet was observed in $9.5 \%$ and in $4.9 \%$ of the children. An anterior cross-bite was documented in $6.4 \%$ of all the examined children. An unilateral posterior cross-bite and a bilateral posterior crossbite were observed in $3.2 \%$ and in $1.5 \%$ of the sample. A posterior edge-to-edge bite was found in $1.9 \%$. A normal overbite was found in $30.1 \%$ of all children; a deep bite with and without gingival contact was registered in $27 \%$ and in $8.5 \%$ respectively; an anterior open bite was seen in $7.2 \%$ of the children and a posterior open bite in $1.3 \%$. The percentage of mandible lateral deviation cases is $2.5 \%$.

Conclusion: Due to the high prevalence of malocclusions with $64.4 \%$, early attention may be given to orthodontic prevention measures.

Keywords: cross-sectional study, occlusal relationship, prevalence, prevention, malocclusions.

\section{Introduction}

The last study conducted on the prevalence of malocclusions in primary dentition in Bulgaria was in the middle of the 80 's, where almost all of the children were included in organized contingents and strictly examined by a dentist or an orthodontist every year. At that time an oral health prevention program was developed, which included orthodontic services for the masses. ${ }^{1,2}$ After the change in health politics, this program is no longer active and occlusal characteristics, prevalence and the types of malocclusions in the primary dentition are not regularly registered and analyzed. An optimal occlusion in primary dentition is essential for the further development of the occlusion in the permanent dentition. $3,4,5,6$ The current preventive program for the Bulgarian children is mostly orientated to caries prevention and according to literature, caries-reducing measures are not likely to have a significant influence on the formation of malocclusions in primary dentition. ${ }^{7}$

We need some present-day data about the prevalence of malocclusions in primary dentition and the aim of this study is to estimate dental

\section{*Corresponding author:}

Dr. Keti Yovcheva, DMD, Department of Orthodontics, Faculty of Dental Medicine, Medical University- Plovdiv, av. Hristo Botev 3, Plovdiv 4000, Bulgaria Tel/Fax: +359.889.623.842/+35.932.631.651, e-mail: drketiyovcheva@gmail.com 
health, prevalence of malocclusions and orofacial dysfunctions in a sample of 4-5-year-old Bulgarian kindergarden children.

\section{Methodology}

The subjects were randomly selected from different kindergardens in the city of Plovdiv. Inclusion criteria were the existence of fully developed primary dentition, no orthodontic treatment, Caucasian origin and a parental consent for participation in the study. A total of 471 boys and girls participated in this cross-sectional epidemiological study. The study was approved by the Ethics Committee of the Medical University Plovdiv (P-7781).

A postgraduate student in Orthodontics carried out the entire diagnostic assessment of all the children. A specific form was designed for the purpose of this study which contains information about dental health, individual occlusion findings and functional status. All the findings were made under good lighting conditions. The metric parameters were recorded by using a metal ruler marked in 0.5 $\mathrm{mm}$. In this paper, all the orthodontic findings will be described and the following parameters have been selected and analyzed:

The type of primary dentition was assessed as follows: with generalized spaces between the teeth and localized spaces (Type 1), no spaces (Type 2) or a crowded dentition (Type 3).

The overjet was measured in $\mathrm{mm}$ as a distance between the labial surface of the lower and upper incisors. A distance of (0-3 $\mathrm{mm}$ ) was defined as a normal distance. An increased overjet was divided into two groups $(3-6 \mathrm{~mm})$ and $(>6 \mathrm{~mm})$, and a negative overjet $(<0 \mathrm{~mm})$, all measured in $\mathrm{mm}$. An anterior cross-bite was registered when one or more maxillary incisors or canines occluded lingually to the mandibular incisors or canines.

The criteria described by Foster \& Hamilton ${ }^{8}$ were used for the primary canine and molar relationship assessment.

- Class I - the tip of the maxillary primary canine tooth is in the same vertical plane as the distal of the mandibular primary canine

- Class II - the tip of the maxillary primary canine tooth is anterior to the distal surface of the mandibular primary canine.

- Class III - the tip of the maxillary canine is posterior to the distal surface of the mandibular primary canine.

Terminal plane relationships of the second primary molar:

- Flush terminal - The distal surfaces of the upper and lower second primary molars are in the same anteroposterior level.

- Mesial step - the maxillary terminal plane is posterior to the mandibular terminal plane

- Distal step - the maxillary terminal plane is anterior to the mandibular terminal plane.

Molar and canine occlusions for each child were recorded separately for the left and the right sides of the dentition.
We have distinguished correct lateral occlusal relationships, a unilateral and a bilateral cross bite, a posterior edge-to-edge bite and a scissor bite. An occlusion of the incisal edges was assessed as an anterior edge-to-edge bite. An overbite was graded according to the coverage of the mandibular incisor by the most protruded maxillary incisor. A normal one, when up to half of the mandibular incisor is covered by the maxillary incisor. An increased overbite, when more than half of the mandibular incisor is covered by the maxillary incisor. An overbite with gingival contact was recorded when the mandibular incisor was fully covered by the maxillary incisor and there was a contact of the incisal edge with the gingiva. An absence of a vertical overlap of the lower incisors was described as an anterior open bite and divided into two groups: moderate $(<3 \mathrm{~mm})$ and severe $(>3 \mathrm{~mm})$.

Collection, evaluation and a statistical analysis of the data were conducted using Microsoft ${ }^{\circledR}$ Excel and SPSS Version 17.0 for Windows ${ }^{\circledR}$ (SPSS Inc., Chicago, IL., USA). Means and standard deviations were determined as descriptive statistical values in order to characterize univariate frequency distributions of various variables. A comparison of absolute frequencies of specific characteristics was tested with Pearson's chi-square test. The statistical significance was assessed at the $5 \%$ level.

\section{Results}

A total of 241 males and 230 females were examined. Normal occlusion relationships were found in $35.6 \%$ of the sample. 126 or $26.8 \%$ of the children have one malocclusion, followed by 129 children or $27.4 \%$ with two malocclusions, 27 or $5.7 \%$ with three malocclusions and then 21 or $4.5 \%$ with four malocclusions. The total distribution of malocclusions is $64.4 \%$.

The most prevalent type of primary dentition is Type 1 with $78.2 \%$ (with spacing), followed by $16.1 \%$ Type 2 (no spacing) and 5.7\% Type 3 (crowding). The gender comparison is shown in Table 1. There is a statistically significant difference between girls and boys in the distribution of spacing, no spacing and crowding which is more prevalent in girls (with spacing $X 2=13,308$, no spacing $X 2=10,429$, crowding $X 2=5,318$ ).

The prevalence of overjet is shown in Table 2. A total of $85.6 \%$ of all the children have a normal overjet, $8.7 \%$ an increased overjet, $0.8 \%$ an excessive overjet and $4.9 \%$ a decreased overjet. Gender and age comparison of the normal, increased and decreased overjet among 4 and 5-year-old boys and girls revealed no statistically significant differences. An anterior cross-bite was registered in $6.4 \%$ of all the children without significant differences in age and sex.

The distribution of different sagittal relationships of primary canine and second primary molars is shown in Table 3 and respectively in Table 4. A neutral occlusion of the primary canines was found in $60 \%$ of all children, a distal occlusion in $30 \%$ 
Table 1. Prevalence of spacing, no spacing and crowding in primary dentition.

\begin{tabular}{|c|c|c|c|c|}
\hline Gender & Type 1 & Type 2 & Type 3 & Total \\
\hline Girls & $172(74.8 \%)$ & $50(21.7 \%)$ & $8(3.5 \%)$ & $230(100 \%)$ \\
\hline Boys & $196(81.3 \%)$ & $26(10.8 \%)$ & $19(7.9 \%)$ & $241(100 \%)$ \\
\hline Total & $368(78.2 \%)$ & $76(16.1 \%)$ & $27(5.7 \%)$ & $471(100 \%)$ \\
\hline
\end{tabular}

Table 2. Prevalence of normal, increased and decreased overjet in 4- and 5-year old children.

\begin{tabular}{|c|c|c|c|c|c|}
\hline Age & Overjet 0-3 mm & Overjet 3-6 mm & Overjet >6 mm & Overjet < $\mathbf{~ m m}$ & Total \\
\hline 4 years & $138(87.9 \%)$ & $10(6.4 \%)$ & $2(1.3 \%)$ & $7(4.5 \%)$ & $157(100 \%)$ \\
\hline 5 years & $265(84.4 \%)$ & $31(9.9 \%)$ & $2(0.6 \%)$ & $16(5.1 \%)$ & $314(100 \%)$ \\
\hline Total & $403(85.6 \%)$ & $41(8.7 \%)$ & $4(0.8 \%)$ & $23(4.9 \%)$ & $471(100 \%)$ \\
\hline
\end{tabular}

Table 3. Primary canine sagittal relationships.

\begin{tabular}{|c|c|c|c|c|c|c|c|}
\multirow{2}{*}{ Age } & \multicolumn{2}{|c|}{ Class I } & \multicolumn{2}{c|}{ Class II } & \multicolumn{2}{c|}{ Class III } & \multirow{2}{*}{ Total } \\
\cline { 2 - 7 } & Right & Left & Right & Left & Right & Left & \\
\hline \multirow{2}{*}{4 years } & 92 & 102 & 45 & 37 & 20 & 18 & 157 \\
& $(58.6 \%)$ & $(65.0 \%)$ & $(28.7 \%)$ & $(23.6 \%)$ & $(12.7 \%)$ & $(11.5 \%)$ & $(100 \%)$ \\
\hline \multirow{2}{*}{5 years } & 181 & 187 & 103 & 100 & 30 & 27 & 314 \\
& $(57.6 \%)$ & $(59.6 \%)$ & $(32.8 \%)$ & $(31.8 \%)$ & $(9.6 \%)$ & $(8.6 \%)$ & $(100 \%)$ \\
\hline \multirow{2}{*}{ Total } & 273 & 289 & 148 & 137 & 50 & 45 & 471 \\
& $(58.0 \%)$ & $(61.4 \%)$ & $(31.4 \%)$ & $(29.1 \%)$ & $(10.6 \%)$ & $(9.6 \%)$ & $(100 \%)$ \\
\hline
\end{tabular}

Table 4. Second molar sagittal relationships.

\begin{tabular}{|c|c|c|c|c|c|c|c|}
\multirow{2}{*}{ Age } & \multicolumn{2}{|c|}{ Flush terminal } & \multicolumn{2}{c|}{ Mesial step } & \multicolumn{2}{c|}{ Distal step } & \multirow{2}{*}{ Total } \\
\cline { 2 - 7 } & Right & Left & Right & Left & Right & Left & \\
\cline { 2 - 7 } & 117 & 119 & 21 & 19 & 19 & 19 & 157 \\
& $(74.5 \%)$ & $(75.8 \%)$ & $(13.4 \%)$ & $(12.1 \%)$ & $(12.1 \%)$ & $(12.1 \%)$ & $(100 \%)$ \\
\hline \multirow{2}{*}{5 years } & 213 & 222 & 52 & 43 & 51 & 47 & 314 \\
& $(67.8 \%)$ & $(70.7 \%)$ & $(16.6 \%)$ & $(13.7 \%)$ & $(16.2 \%)$ & $(15.0 \%)$ & $(100 \%)$ \\
\hline \multirow{2}{*}{ Total } & 330 & 341 & 73 & 62 & 70 & 66 & 471 \\
& $(70.1 \%)$ & $(72.4 \%)$ & $(15.5 \%)$ & $(13.2 \%)$ & $(14.9 \%)$ & $(14.0 \%)$ & $(100 \%)$ \\
\hline
\end{tabular}

and a mesiocclusion in $10 \%$. A distribution of a flush terminal molar relationship in percentages is $70.1 \%$ on the right side and $72.4 \%$ on the left side of the examined subjects. The mesial step was assessed as $15.5 \%$ on the right side and $13.2 \%$ on the left side. And the distal step was assessed as $14.9 \%$ on the right side and respectively $14 \%$ on the left side. There are no statistically significant differences between gender in the primary canine relationships and the second primary molar relationships. But we found a statistically significant increase in Class II canine relationships between the age groups ( $X 2=3.479, p=0.062)$.

A normal overbite was found in $30.1 \%$ of the sample and an anterior edge-to-edge bite existed in $27.2 \%$ of all the children, with no significant differences between gender and age in the subgroups. A moderate anterior open bite $(<3 \mathrm{~mm})$ and a severe anterior open bite $(>3 \mathrm{~mm})$ were registered respectively in $6.8 \%$ and $0.4 \%$. A posterior open bite was documented in $1.3 \%$ of all children. A deep overbite was found in 127 children (27.0\%) and a deep overbite with gingival contact in 40 children (8.5\%). Statistically significant was the fact that boys showed more deep bites with gingival contact ( $X 2=3.347, p=0.067)$ and also the difference between the age groups was statistically significant ( $X 2=3.497, p=0.061)$ - an increase of the frequency was observed with the increasing of the age.

A unilateral posterior cross-bite was observed in $3.2 \%$ of the sample and a bilateral posterior cross-bite in $1.5 \%$. An edge-to-edge bite in the posterior region was found in 9 cases with a statistically significant difference in age comparison (X2 = 8.156, $p=0.004)$, the 4-year-olds showed more edge-to-edge bites than the 5-year-olds. In this sample, a scissor bite was not registered. The total percentage of mandible lateral deviation was $2.5 \%$. A mandible deviation to the right side was found in two cases and 10 cases to the left side. The percentage prevalence of malocclusions in primary dentition is shown in Table 5. 
Table 5. Percentage prevalence of malocclusions in primary dentition.

\begin{tabular}{|c|c|c|}
\hline Type of malocclusion & Children with malocclusion & Percentage (\%) \\
\hline Class II canine occlusion & 142 & $30.1 \%$ \\
\hline Class III canine occlusion & 45 & $9.6 \%$ \\
\hline Anterior open bite & 34 & $7.2 \%$ \\
\hline Posterior open bite & 6 & $1.3 \%$ \\
\hline Deep overbite & 127 & $27 \%$ \\
\hline Deep overbite with gingival contact & 40 & $8.5 \%$ \\
\hline Anterior cross bite & 30 & $6.4 \%$ \\
\hline Posterior cross bite & Unilateral - 15 & $3.2 \%$ \\
\hline Posterior edge-to-edge bite & Bilateral - 7 & $1.5 \%$ \\
\hline Mandible lateral deviation & 9 & $1.9 \%$ \\
\hline
\end{tabular}

\section{Discussion}

The overall prevalence of malocclusions is high - $64.4 \%$. According to the scientific literature, the prevalence of malocclusions in primary dentition varies from $22 \%$ to $93 \%$ \%,10 due to racial characteristics and different occlusion recording methods. We found a higher prevalence of malocclusions as compared to some previous studies conducted on the Bulgarian population by Nikolov \& Atanasov, ${ }^{11}$ who found $44.5 \%$ prevalence. The difference in prevalence is probably due to the fact that at that time a mass orthodontic prevention program was held. The generalized spacing in this sample is $78.2 \%$ and it is corresponding to the findings of Foster\&Hamilton ${ }^{8}$ with $70 \%$. The prevalence of no spacing and crowding concurs with other studies, ${ }^{4,12,13}$ but it is much lower than the results for the British children. ${ }^{8}$ Our results for the prevalence of several concurrent malocclusions in primary dentition are in agreement with other studies. ${ }^{14}$ The canine sagittal relationships showed that $60 \%$ of the children have Class I, 30\% have Class II and 10\% have Class III and the results are corresponding to the findings for the European population. ${ }^{4,10,15}$

Our study conducted on the Bulgarian population showed a percentage distribution of a flush terminal molar relation in $70.1 \%$ of the subjects on the right side and $72.4 \%$ on the left, which is similar to studies done by Nanda et al. ${ }^{16}$ A mesial step and a distal step in this sample are equally distributed in $14.4 \%$ and $14.5 \%$, respectively. Our results for the mesial step are in agreement with the findings of Baume ${ }^{17}$ and Ravn, ${ }^{18}$ but in disagreement with the results of Johannsdottir et al., ${ }^{19}$ who found that $60 \%$ of their sample had mesial step occlusal relationships in primary dentition. Our results for the distal step are similar to the findings by Grabowski et al., ${ }^{10}$ who found $15.5 \%$ "distalization" in primary dentition.

The normal overjet is in agreement with the results by Berneburg et al., ${ }^{14}$ but the increased overjet was assessed in $9.5 \%$ of this sample, which is lower than their findings. Our results for the decreased overjet are higher than other studies ${ }^{10,14}$ but similar to the findings of Müssig. ${ }^{15}$ An anterior cross-bite was observed in $6.4 \%$ of the sample, which resembles a study conducted by Kerouso ${ }^{20}$ for the Finnish children.

The prevalence of a normal overbite is $30.1 \%$. We also found $27.2 \%$ of an anterior edge-to-edge bite and, at the age of 5, it is a norm according to Hotz. ${ }^{21}$ The findings are in agreement with the results by Nanda et al., ${ }^{16}$ Müssig ${ }^{15}$ and Berneburg et al. ${ }^{14}$ But on the other hand, the high frequency may be due to the self-correction of an anterior open bite after interrupting the action of external factors. ${ }^{22}$ In this sample, a moderate anterior open bite $(<3 \mathrm{~mm})$ and a severe anterior open bite $(>3 \mathrm{~mm})$ were registered respectively in $6.8 \%$ and $0.4 \%$ of the children, which is in agreement with Berneburg et al., ${ }^{14}$ who found $4.6 \%$ prevalence of an anterior open bite. The prevalence of an anterior open bite in this sample is significantly less than the findings of Müssig ${ }^{15}$ and Tschill et al. ${ }^{4}$

Our results showed prevalence of a deep bite and a deep bite with gingival contact, $27 \%$ and $8.5 \%$, respectively, which is similar to the studies done by Müssig ${ }^{15}$ and Grabowski et al. ${ }^{10}$ In this sample, boys have more severe deep bites and there is also a statistically significant increase in prevalence of a deep bite with gingival contact with the increasing of the age, which concurs with other studies' results, ${ }^{10,22}$ but it is in disagreement with the results of Berneburg et al. ${ }^{14} \mathrm{~A}$ posterior cross-bite was seen in $4.7 \%$ and a posterior edge-to-edge bite in $1.9 \%$ of all the children in this study.

Other investigators report that a deciduous posterior cross bite ranges between 7-12\%.8,10,18 But our findings are similar to Hensel (12) and Stahl \& Grabowski, ${ }^{6}$ who report $5.1 \%$ and $4 \%$ respectively. Available literature suggests that the development of the occlusion and oral functions in primary dentition is a continuum for the further morphological and functional development of the stomatognathic system. 4,10 The correct development of a stable, functional and aesthetically acceptable occlusion is an integral component of a comprehensive oral 
health care for all pediatric dental patients. ${ }^{23}$ Further research is needed to establish the development of the dentition and malocclusions in the next stages of the dental development in this sample, and the relatively small sample size is a limitation of our study.

\section{Conclusions}

This cross sectional study provides present-day data about the prevalence of malocclusions in a sample of 471 Bulgarian children with primary dentition. Statistical differences in the type of dentition, a deep bite with gingival contact and a posterior edge-toedge bite were found. Class II canine occlusion, a distocclusion, a deep bite, no spacing and crowding and an increased overjet were the epidemiologically- relevant malocclusions in our study.

Due to the high prevalence of malocclusions in deciduous dentition, it is necessary for children to be regularly examined at an early age and the occlusal development should be individually assessed. Early attention may be given to malocclusions and their prevention, and especially to those caused by external etiologic factors like bad habits and incorrect oral functions.

\section{Acknowledgments}

The authors declare no conflict of interest related to this study. There are no conflicts of interest and no financial interests to be disclosed.

\section{References}

1. Atanasov K. Orthodontic prevention for the masses in Bulgarian. Dissertation, Plovdiv, Bulgaria: Medical University - Plovdiv ${ }_{\text {, }}$ 1989;8-10.

2. Mutafchiev V, Dinkova M, Hranova V. [Distribution of malocclusions and their main etiologic factors in kindergarten children in Bulgarian]. Stomatologiia. Stomatology.1988;70(3):55-61. Bulgarian.

3. Varrela J, Alanen P. Prevention and early treatment in orthodontics: a perspective. J Dent Res. 1995;74(8):1436-1438. doi: 10.1177/00220345950740080101 [Full text links] [PubMed] Google Scholar (37) Scopus (17)

4. Tschill P, Bacon W, Sonko A. Malocclusion in the deciduous dentition of Caucasian children. Eur J Orthod. 1997;19(4):361-367

[PubMed] Google Scholar (153) Scopus (59)

5. Kerosuo H. The role of prevention and simple interceptive measures in reducing the need for orthodontic treatment. Med Princ Pract. 2002;11Suppl 1:16-21. Review. [PubMed] Google Scholar (16) Scopus (4)

6. Stahl F, Grabowski R. Orthodontic findings in the deciduous dentition and early mixed dentition -inferences for a preventive strategy. J Orofac Orthop. 2003;64(6):401-416. doi: 10.1007/s00056-003-0313-8 [Full text links] [PubMed] Google Scholar (90) Scopus (33)

7. Stahl F, Grabowski R. Malocclusion and caries prevalence: is there a connection in the primary and mixed dentitions? Clin Oral Investig. 2004;8(2):86-90. doi: 10.1007/s00784-003-0244-1 [Full text links] [PubMed] Google Scholar (61) Scopus (28)

8. Foster TD, Hamilton MC. Occlusion in the primary dentition. Study of children at 2 and one-half to 3 years of age. Br Dent J. 1969;126(2):76-79. [PubMed] Google Scholar (288) Scopus (126)

9. Thilander B, Pena L, Infante C, Parada SS, de Mayorga C.. Prevalence of malocclusion and orthodontic treatment need in children and adolescents in Bogota, Columbia. An epidemiological study related to different stages of dental development. Eur J Orthod. 2001;23(2):153-167.

[PubMed] Google Scholar (444)

10. Grabowski R, Stahl F, Gaebel M, Kundt G. [Relationship between occlusal findings and orofacial myofunctional status in primary and mixed dentition. Part l: Prevalence of malocclusions]. J Orofac Orthop. 2007;68(1):26-37. doi: 10.1007/s00056-007-1606-0. German. [Full text links] [PubMed] Scopus (47)

11. Nikolov B, Atanasov K. [Development of dental arches from 3 to 6 years of age at norm and malocclusion] Stomatologiia. Stomatology. 1982;64(3):208-214. Bulgarian.

12. Hensel E. [Investigations on the development of malocclusions from the primary dentition to the mixed dentition] Fortschr Kieferorthop. 1991;52(6):353-358. German.
Google Scholar (18) Scopus (14)

13. Abu-Alhaija ES, Qudeimat MA. Occlusion and tooth arch dimensions in the primary dentition of preschool Jordanian children. Int J Paediatr Dent. 2003;13(4):230239

Google Scholar (90) Scopus (30)

14. Berneburg M, Zeyher C, Merkle T, et al. Orthodontic findings in 4- to 6-year-old kindergarten children fromsouthwest Germany. J Orofac Orthop. 2010;71(3):174-186. doi: 10.1007/s00056-010-9941-y [Full text links] [PubMed] Google Scholar (3) Scopus (2)

15. Müssig D. [The type and incidence of mandibular abnormalities and functional disorders in the deciduous dentition]. Fortschr Kieferorthop. 1991;52(2):110-114. German.

[PubMed] Google Scholar (2)

16. Nanda RS, Khan I, Anand R.Age changes in the occlusal pattern of deciduous dentition. J Dent Res. 1973;52(2):221-224. doi:

$10.1177 / 00220345730520020601$

[Full text links] [PubMed] Google Scholar (88) Scopus (27)

17. Baume LJ. Physiological tooth migration and its significance for the development of occlusion. I. The biogenetic course of the deciduous dentition. J Dent Res. 1950;29(2):123-132. doi: $10.1177 / 00220345500290020301$

[Full text links] [PubMed] Google Scholar (526) Scopus (90)

18. Ravn JJ. Longitudinal study of occlusion in the primary dentition in 3-7-year old children. Scand J Dent Res. 1980;88(3):165-170 [PubMed] Google Scholar (37)

19. Johannsdottir B, Wisth PJ, Magnusson TE. Prevalence of malocclusion in 6-year-old Icelandic children. Acta Odontol Scand. 1997:55(6):398-402

[PubMed] Google Scholar (87) Scopus (47)

20. Kerosuo H. Occlusion in the primary and early mixed dentitions in a group of Tanzanian and Finnish children. ASDC J Dent Child 1990;57(4):293-298. [PubMed] Google Scholar (99) Scopus (48)

21. Hotz R. [Dentistry for children and adolescents] German. 2 ed, Stuttgart, Georg Thieme Verlag; 1981; 280-292.

22. Dimberg L, Lennartsson B, Arnrup K, Bondemark L. Prevalence and change of malocclusions from primary to early permanent dentition: a longitudinal study. Angle Orthod. 2015;85(5):728-734. doi: 10.2319/080414-542.1

[Full text links] [PubMed] Google Scholar (39) Scopus (15)

23. Majorana A, Bardellini E, Amadori F, Conti G, Polimeni A. Timetable for oral prevention in childhood-developing dentition and oral habits: a current opinion. Prog Orthod. 2015;16:39. doi: 10.1186/s40510-0150107-8

[Full text links] [Free PMC Article] [PubMed] Google Scholar (4) 


\section{Keti YOVCHEVA}

DDS, PhD, Postgraduate Student

Department of Orthodontics

Faculty of Dental Medicine

Medical University - Plovdiv, Bulgaria

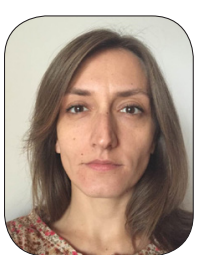

Dr Keti Yovcheva, DDS is a PhD and postgraduate student at the Department of Orthodontics, Faculty of Dental Medicine, in Medical University - Plovdiv, Bulgaria. Since 2010 she has been working as an assistant doctor at a private orthodontic practice. One of her main research interest is preventive and interceptive orthodontics.

\section{Ouestions}

Which is the most prevalent type of primary dentition found in this study?

$\square$ a. Type 1;

b. Type 2;

c. Type 3;

$\square$ d. none of them.

\section{What is the total prevalence of malocelusions found in this study?}
a. $54.4 \%$;
b. 64.4\%;
c. $74.4 \%$;
d. $82.5 \%$.

\section{What is the prevalence of anterior open bite found in this study?}
a. 5.8\%;
b. 6.0\%;
c. $6.4 \%$;
a d. $6.8 \%$.

What is the prevalence of unilateral posterior cross bite found in this study?
a. $4.5 \%$;
b. $4.2 \%$;
c. $3.2 \%$;
a d. $3.0 \%$.

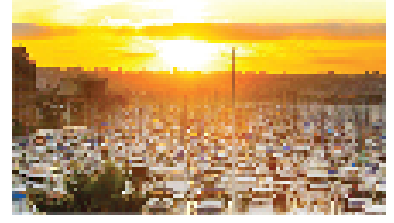

\section{$\sqrt{\Gamma}$ The 25th International Symposium on Ceramics}

\section{The New Frontiers of Esthetic Excellence: Successtully integrating the Best of Traditional and Digital Dentistry}

